Special issue.2005.V 1.N 4.P. 56-62.

\title{
PATENT WAREHOUSE: STRATEGIC ALLIANCES FOR COMMERCIALIZATION OF INTELLECTUAL PROPERTY IN CENTRAL \& EAST EUROPE
}

\author{
*James D. Laur \\ J.D., Deputy General Counsel, Department of Legal Affairs, Cedars-Sinai Medical Center
}

\section{**Douglas Shin}

B.A. (J.D. candidate '06), Loyola Law School; Technology Transfer Intern, Department of Academic Affairs, Cedars-Sinai Medical Center

\section{** Sandor G. Vari}

MD, International Research and Technology Transfer Manager, Burns and Allen Research Institute, Department of Academic Affairs, Cedars-Sinai Medical Center

\begin{abstract}
*Attorney James D. Laur received his Juris Doctor (J.D.) degree, cum laude, from the Boston College School of Law in 1986. In addition, Mr. Laur received his Bachelor of Arts (B.A.) degree, cum laude, with a double major in Political Science and Philosophy from the University of California, Los Angeles (UCLA) in 1983. Mr. Laur worked as an associate attorney in the International Corporate Department of the Dutch law firm of Van Doorne \& Sjollema Advocaten (Rotterdam, The Netherlands) from 1986 to 1989. From 1989 to 1991, Mr. Laur worked in the Corporate Department of the law firm McDermott \& Trayner (Pasadena, California). From 1991 to the present, Mr. Laur has been an attorney in the Legal Affairs Department of Cedars-Sinai Medical Center (Los Angeles, California). Mr. Laur is currently Cedars-Sinai's Deputy General Counsel and is primarily responsible for all intellectual property (patent/trademark/copyright) matters for Cedars-Sinai's Burns \& Allen Research Institute and is lead counsel for Cedars-Sinai's Technology Transfer Office. Mr. Laur is a frequent speaker on intellectual property issues and the management of technology transfer programs in the academic sector. E-mail: James.Laur@cshs.org.
\end{abstract}

**Douglas Shin graduated from the University of California, San Diego with a Bachelors of Art (B.A.) degree in History and a minor in Biology. He is currently a third year law student at Loyola Law School in Los Angeles and a member of the Loyola Law Review. He is a candidate for a Juris Doctor (J.D.) degree in the Spring of 2006. In addition, Mr. Shin is an intern in the Technology Transfer Office at Cedars-Sinai Medical Center.

*** Short resume of Sandor G. Vari, MD is available in the article: Research and Innovation Strategic Alliance of Cedars-Sinai Medical Center and Central - Eastern European (CEE) Academic Organizations. 


\section{INTRODUCTION}

The "Patent Warehouse" is a concept involving the creation of a strategic alliance among Central and East European (CEE) academic institutions in order to enhance each individual institution's technology transfer efforts. The Patent Warehouse has the potential to bring participating CEE universities access to shared innovation management expertise and, ultimately, increased opportunities for licensing and royalty income. The consortium would essentially combine the efforts of participating CEE institutions together, allowing members to establish a more attractive intellectual property (IP) portfolio and a stronger negotiating position when dealing with outside companies interested in IP placed by its members in the Patent Warehouse.

This article addresses the need for CEE institutions to come together and pool their economic and technology transfer resources and specifically discusses the proposed Patent Warehouse concept that we believe could effectively fill this need. Part II discusses the compelling reasons for the proposed formation of the Patent Warehouse. Part III provides the blueprint for proper implementation and operation of the Patent Warehouse. Finally, Part IV of this commentary will discuss both the benefits and potential obstacles emerging from a Patent Warehouse alliance.

\section{THE CURRENT ENVIRONMENT IN THE CEE COUNTRIES PREVENTS EFFICIENT PROMOTION AND MARKETING OF INSTITUTIONAL INVENTIONS}

With the unraveling of the iron curtain in the late 1980's, the CEE countries became free to participate in the free-market system. However, CEE countries have been slow to implement and take advantage of this system because of pre-existing political, social and economic barriers. Likewise, the academic institutions in the CEE countries have struggled to efficiently market and license IP produced in their facilities.

CEE academic institutions currently have informal or outdated policies, if any at all, about intellectual property developed at their facilities. Some institutions allow researchers to retain full ownership of any IP created at the institution while other institutions have more control over IP created in their facilities. Some institutions are confronted with contradictory and often confusing overlay of ownership claims to IP developed at the institution. The lack of consistent administrative rules and clear national legislation regarding the ownership rights to IP created at academic institutions throughout the CEE hurt both the inventors and the institutions and, ultimately, also the country itself. Inventors lose great opportunities for commercially appropriate licensing and can severely underestimate the value of the IP they produce and end up selling ownership rights to for-profit companies for little, if any, financial gain. Institutions also lose financial opportunities because they may not provide sufficient administrative support and incentive for investigators to entrust the administration with their IP. It goes without saying that if the IP is being acquired without fair payment, the country loses the valuable income stream into its academic institutions and the national economy.

Additional external factors such as political corruption, constantly changing and often contradictory legislation, intra-institutional bureaucracy and lack of substantial foreign investment in CEE countries have also contributed heavily to the slowed transition to a free-market system. As a result, it is easy for large outside companies to exploit the researchers and/or institutions by offering minimal financial compensation in exchange for licensing rights or outright ownership of the IP. 


\section{Special Issue}

This inability to take advantage of market opportunities is a familiar occurrence worldwide at many non-profit and academic institutions. For example, in 1968, Cedars-Sinai Medical Center lost the opportunity to protect and license the famous Swan-Ganz catheter because the inventors sold the rights to the device to an outside company for a mere $\$ 10,000$. The commercial distributors of the catheter earned millions of dollars from the success of the device, while Cedars-Sinai received nothing. It is easy to imagine how the research program of the academic medical center could have been enhanced and further developed if the institution had received a fair share of the proceeds from the commercialization of the technology developed in its laboratories. Decades later, with a Technology Transfer Office in place along with clear institutional policies governing the ownership and responsibility for marketing all IP from the institution, Cedars-Sinai was able to license another device called the Barath-Balloon catheter which, to date, has earned over $\$ 28$ million in royalty income which has been reinvested into the institution's charitable mission of research and community service. This drastic reversal of fortune occurred because Cedars-Sinai recognized that valuable technology was being created in its laboratories and, therefore, established and enforced an IP policy allowing the institution to effectively market its IP and foster a mutually beneficial relationship between the institution and its researchers.

The same turnaround is also possible for CEE academic institutions if they take the proper steps to implement an effective innovation management system. Furthermore, a Patent Warehouse alliance could greatly enhance the potential economic rewards for CEE institutions by leveraging the collective expertise of the participants to evaluate the IP in the Patent Warehouse and simultaneously enhancing the bargaining position of member institutions with potential licensees who are more likely to be attracted to a broader and deeper IP portfolio for licensing opportunities. For CEE universities to reach their full potential with their technology transfer efforts, several steps are first required to implement an effective system of IP protection, promotion and marketing.

\section{THE FORMATION OF THE PATENT WAREHOUSE INVOLVES COOPERATIVE PATENT POOLING/MANAGEMENT AND EXTENSIVE EDUCATION OF MEMBER INSTITUTIONS' TECHNOLOGY TRANSFER OFFICES}

The alliance envisioned in a Patent Warehouse would provide member institutions opportunities and expertise previously unavailable to them. However, before an institution is in a position to take advantage of the Patent Warehouse alliance, a Technology Transfer Office with functioning policies and procedures governing IP at the institution needs to be in place. It is only with its own institutional process in place can an institution be a successful participant in the Patent Warehouse and actually transfer IP rights into the Patent Warehouse.

\section{A. Each Member Institution Needs to Have a Technology Transfer Office and Administrative Support in Place to Help Facilitate the Smooth Transition of IP to the Warehouse}

A Technology Transfer Office (TTO) exists for the benefit and convenience of both the academic institution and the researcher producing the IP. It is important for the institutions and their researchers to work with their TTO because the TTO can act as a buffer against undue influence of an outside company interested in a researcher's IP. In addition, the TTO can and, in fact, must be a strong advocate for the 


\section{Technologies, innovation management and technology transfer}

researcher and the institution in its licensing efforts. In order to be effective, a TTO needs to be able to provide an honest assessment of both the uniqueness and potential value of the technology within the particular field of science and the relevant commercial market. A thorough analysis of a technology's commercial value often includes examination of competing technologies, market penetration potential, actual commercial sales estimates and, if necessary, a third-party marketing analysis of the technology. A realistic IP valuation is crucial to a TTO's success because the patent process is both lengthy and costly. Patents are expensive to obtain and maintain and should not be pursued if the IP has no true licensing potential.

In addition, institutions need to recognize the importance of establishing their legal claims to the IP produced in their labs. The lack of clear ownership rights in the IP leads to delays in the licensing process at a minimum or, at worst, makes the IP impossible to license at all. An outside company will be reluctant to take a license and invest in developing a technology if the IP ownership rights are not clearly in the hands of the institution. The academic institutions in the CEE must work at the national level, if necessary, to ensure that the ownership rights in the academic field are clearly defined in the relevant national legislation. Then, equally important, the institution must ensure that it has established and implemented policies and procedures governing the disclosure, ownership, management and ultimate commercialization of inventions arising on campus. Many institutions are coming to recognize that a key policy for the success of an innovation management process is a commitment by the institution to share a percentage of the net proceeds from any successful license with the individual inventor or inventors of the technology licensed. By rewarding inventors personally for cooperating with the TTO, the institution can increase the likelihood that its researchers will respect and abide by the insitutional policies for managing IP rights. It is also worth noting that a TTO should work closely with outside legal counsel during the valuation and patent prosecution processes. Patent attorneys specialize in the protection of IP rights and should be expected to provide advice and assistance with the commercial valuation process and licensing strategy for a technology. However, the challenge for the CEE academic institutions is the lack of experienced personnel familiar with innovation management and the ability to afford legal professionals which is more and more necessary for the TTO to be successful. Therefore, the Patent Warehouse model may be an attractive solution to providing this missing expertise and licensing contacts for enhancing the probabilities for technology transfer success.

\section{B. The Patent Warehouse Will House and Maintain Various Patent Portfolios of Member Institutions}

The Patent Warehouse system can consolidate the individual IP portfolios of participating CEE academic institutions into a collective academic powerhouse and, if structured correctly, can provide the technology transfer expertise missing at the individual institutional level. In addition, the Patent Warehouse structure can simultaneously increase the financial bargaining position for each member. The system involves trust, cooperation and a commitment to participate actively in the Patent Warehouse by CEE institutions who agree to join the consortium.

First, as indicated above, each academic institution must take control of new IP produced in its research facilities. The individual TTO at each institution would need to be committed to placing technology from its institution into the Patent Warehouse. The Patent Warehouse would then take the lead to assess the potential value and, if appropriate, market the IP to interested companies. 
C. The Patent Warehouse Will Have a Qualified Manager With the Experience and Expertise Necessary to Train TTOs and Oversee Proper Valuation and Licensing of the IP Portfolios in the Patent Warehouse

For the Patent Warehouse consortium to succeed, the presence of a well-qualified, experienced manager is essential. The Patent Warehouse management would be crucial to the initial formation and maintenance of the consortium. As stated above, CEE institutions may determine that they currently lack the necessary experience in the IP valuation and marketing processes. Cedars-Sinai Medical Center has a long history in licensing and maintaining IP portfolios. In addition, Cedars-Sinai has seen its share of commercial licensing successes, learned from past mistakes and has refined its IP valuation and marketing policies over time. CedarsSinai has been working with its partner academic institutions in CEE for the past few years to provide educational assistance for establishing an innovation management program and providing technology transfer services for the new TTOs opened at the various institutions in the region.

Initially, the Patent Warehouse would, we believe, need to contract with an established institution, such as Cedars-Sinai, to act as the first manager for the Patent Warehouse and assist in training and teaching TTOs in the consortium. Over time, as member institutions gain more experience by participating in the IP valuation and licensing process, the Patent Warehouse manager role should gradually transition from being served by an established and experienced consultant to being managed completely by an individual or team that would, optimally, come from the TTO staff at one or more of the participating CEE institutions. One primary goal, in fact, of the Patent Warehouse model that we envision is the empowerment of the TTO professionals by pro- viding hands on education about technology transfer best practices so that the institutional members of the Patent Warehouse will all benefit not only financially from successful licensing activities but also through the dissemination of know-how about innovation management to the region.

\section{THE PATENT WAREHOUSE WILL PROVIDE CEE INSTITUTIONS WITH THE OPPORTUNITY TO FLOURISH FINANCIALLY AND LEARN BEST PRACTICES THROUGH HANDS-ON PARTICIPATION AND TRAINING, BUT FACES FORESEEABLE OBSTACLES}

A Patent Warehouse alliance gives participating CEE institutions several important advantages. First, the consortium arrangement allows member institutions to include their IP into a bigger portfolio of technology collected from other institutions and held by the Patent Warehouse which will attract more interest from potential licensees. Second, member institutions would have an easier time marketing and licensing their technology because the TTOs and Patent Warehouse manager would work together to evaluate the IP and market it to companies (either directly or as a part of a transaction with a venture capitalist to create, for example, a "spin-off" company). Third, the TTO professionals at each institution will be educated about best practices for a successful innovation management system and gain invaluable handson experience with the basic steps of the process: assessment, protection and commercialization of IP rights. However, there are predictable obstacles that can hinder the growth and undermine the potential for success of the Patent Warehouse alliance.

Although the Patent Warehouse consortium can serve as a platform to bring CEE institutions together, competition among the participants and institutional self-interest can still be 


\section{Technologies, innovation management and technology transfer}

present. Individual institutions may feel that they are contributing more valuable IP and licenses to the alliance than other member universities or feel reluctant to participate fully until they see what the other participants will be contributing to the Patent Warehouse. A foreseeable result of this attitude is the temptation for a researcher or an institution to circumvent the consortium and attempt to broker a deal independently with an outside company which has shown interest in the technology. The temptation to act outside the Patent Warehouse increases when the IP appears to have potentially high commercial value. The fact remains, however, that the institution on its own will, more likely than not, be unable to secure a license from the company which maximizes the return of value to the institution. Without the access to the strength that the Patent Warehouse would have brought to the negotiation table along with the skills and expertise of the Patent Warehouse management, the academic institution will find itself at a disadvantage.

One way that the Patent Warehouse will be able to overcome problem of institutional reluctance to participate is by taking each opportunity that is in the Patent Warehouse and working its best to negotiate licensing agreements that lead to financial success. The successful marketing and licensing of IP in the Patent Warehouse portfolio will go far in assure member institutions that the Patent Warehouse alliance is the best way for the institution to achieve its goal of success with its innovation management system. Each success, big and small, will combine over time to reassure Patent Warehouse members that this new concept is worthwhile. Other institutions in the CEE region will undoubtedly also see the growing economic success of the Patent Warehouse and will want to become members and share in the financial and educational rewards. We envision that the Patent Warehouse model can grow over time to incor- porate IP from new institutional partners, however, each candidate for membership would have to convince the existing membership that they have the requisite ownership issues and institutional innovation management policies and procedures in place before the candidate could be admitted into the Patent Warehouse alliance.

As described above, the Technology Transfer Office is an essential tool for institutions and researchers to have in the promotion of IP. While appointing qualified individuals to TTO positions and providing adequate administrative support seems simple enough, the actual integration and implementation of the TTO and the IP policies into the institutional administrative process and power structure can be lengthy and often painful. In reality, the actual valuation of IP can be difficult and remains a challenge for even the most experienced TTOs in Western institutions. This is the area where the Patent Warehouse alliance would prove to be the most helpful. The Patent Warehouse alliance would lower the intimidating and steep learning curve that TTOs typically face by providing intensive education and close guidance about best practices for innovation management. In particular, the Patent Warehouse manager would help enhance the TTO's abilities by teaching and guiding the crucial steps in the process of IP valuation and licensing. This is similar to the "Innovation Management and Technology Transfer" (IMTT) training program that Cedars-Sinai Medical Center has in place with a number of academic institutions in the CEE. In brief, the IMTT training program provides CEE institutions with the basic building blocks of an innovation management system, explains why a TTO is necessary and teaches the institutional leadership the necessary steps involved in implementing a technology transfer program. A number of CEE universities have participated in the IMTT training program and have sent representatives to visit Cedars-Sinai for a ten- 


\section{Special Issue}

day period to attend a consolidated series of educational experiences provided by the technology transfer personnel at Cedars-Sinai.

One last challenge that CEE institutions face in the establishment of a TTO and implementation of the related innovation management polices is the distinct feeling of isolation. Because the field of technology transfer is so relatively new to the region's academic community, there has been an absence of people experienced in this activity and limited avenues for professional development. The Patent Warehouse alliance would serve to fill this void and provide members with an additional perspective into the IP process. While most academic institutions must struggle on their own to develop their own TTOs and implement new and potentially unwelcome ownership polices, individuals from the TTOs of institutions participating in the Patent Warehouse would be able to communicate freely with and learn from their colleagues from other institutions. The existence of a coalition allows each institutional TTO the luxury of turning to other TTOs in the alliance and the Patent Warehouse management for advice, direction and, in some cases, simply someone to commiserate with.

\section{CONCLUSION}

The academic community in Central and East Europe is home to many of the world's top academics and research institutions and there is a long historical tradition of scientific excellence. However, these institutions have yet to reap substantial economic benefits from IP developed in institutional research laboratories that many Western academic institutions enjoy. The formation of a Patent Warehouse alliance would, we believe, serve to protect and promote the innovations created at the universities and allow the member institutions to receive fair market value for the IP that arrises from their research and administrative efforts. Despite the existence of several foreseeable obstacles, the successful licensing and return of revenue to member institutions will ensure the success of the consortium. Ultimately, the Patent Warehouse is a model which could ensure that CEE institutions receive a continuous revenue stream from their inventions and allow both the institutions and researchers to benefit by providing much needed funding for the research programs and enhanced recognition for the valuable advances made in the various fields of science. 